\title{
A Study to Determine the Level of Satisfaction among the Nurses at Federal Medical Centre, Umuahia South East of Nigeria
}

\author{
Article by Okam, Nwakaego \\ Intensive Care Unit Federal Medical Centre, Umuahia, Abia State, Nigeria \\ Email:-udookam@gmail.com
}

\begin{abstract}
Job satisfaction is one of the criteria of establishing a healthy organizational structure in an organization. Nurses are inseparable cornerstone of the health system. Job satisfaction of these nurses will affect the quality of career rendered in our healthcare centers. In this respect the question of how the elemental factors affect their level of satisfaction becomes important. This paper tried to examine the level of job satisfaction among the nurses.

This is a cross-sectional study conduct to determine the level of job satisfaction among nurses in their workplace. A total of 193 self administered questionnaire were obtained for data analysis. The subjects' were selected randomly. Internal consistent reliability by Cronbach's alpha coefficient test was 0.706 .

The result showed that nurses job satisfaction is moderate-high. The null hypothesis for age and marital status was upheld at, age-p-value 0.8028 and marital status-P-Value 0.145. But for education $P$-Value $<0.0001$ and years of experience is $P$-Value $<0.00001$ too. The finding is important for understanding level of job satisfaction and are milestone to improve quality nursing care/services at the centre. It is recommended that management should be encouraged to sustain profitable policies to motivate the nurses.
\end{abstract}

Keywords: Job satisfaction, Nurses, factors of job satisfaction.

\section{Introduction}

\section{Background}

Job satisfaction is a concept that behavioral scientist have emphasized in recent years. It has important impact on organizational goal accomplishment, employee health and well being and more importantly to patient care. (Demur 2002)

Job satisfaction as a matter of fact is an important component of nurses' lives that can impact on patient safety, staff morale, productivity and performance, quality of care, retention and turnover, commitment to organization and profession with additional replacement costs. (Saifuddin 2008).

Nursing is a component and the backbone of health care delivery system. High turnover and absenteeism often reported are related to job dissatisfaction, while low absenteeism is associated with high job satisfaction (Johnson and Johnson 2000; Murrels, Robinson and Maben 2008).

According to previous research, it is has been noted that job satisfaction among nurses is low or at most moderate. In Nigeria, the situation is not different, evidenced by the increased rate of industrial action and agitation for one thing or the other.

\section{Conceptual framework}

The conceptual framework of this study is based on Herzbegs two factor theory model. Job satisfaction stem from different sources certain factors lead to satisfaction when they are present and dissatisfaction when they are absent.

Herzbeg tried to expand the work of Maslow by developing a content theory of work motivation. Using the critical incident method of data analysis he reported that god feeling were generally associated with job experience and job content. Report good feelings were generally associated with job experience and job content and vice versa. 


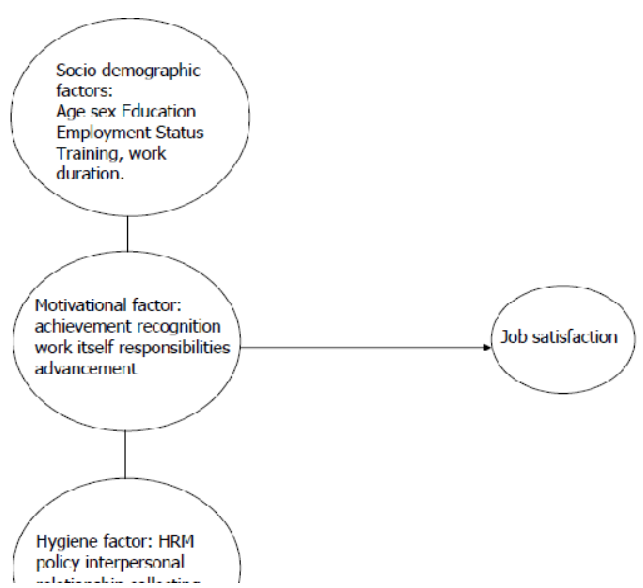

Figure 1: Model of job satisfaction

The content of the above model determines ones level of satisfaction at work. (Al.Hussani 2008, Adams and Bonde 2002).

As put by Mohamed is characterized as multidimensional with six facets- satisfaction with supervisor, job variety closure, compensation, co-workers and human resource and management policies. These factors determines the satisfaction a nurse perceives in his/her job and will be adopted in this study as measures for level used by Purani and Sahdi (2007)

\section{Statement of problem}

Shortage of nurses is a serious problem around the world which affects standard of nursing care. In recent times, nurses are either leaving their job for greener pasture or changing career entirely just because of the discontentment of their nursing job.

Little is known about job satisfaction of nurses especially in Federal Medical Centre Umuahia. This lack of knowledge is problematic because there is a well-documented connection between job satisfaction and well-being of nurses and patient/clients. Hospitals have generally been identified as a difficult place to work in: nurses burnout is common, litigation and bullying is on the increase, turnover is high. Furthermore, physical and emotional challenges that face nurses are almost notable.

In Federal Medical Centre, Umuahia, the story is not different. Since vital organization economic outcomes are related to work satisfaction, therefore the hospitals should access levels of satisfaction with their organization. In this study various aspect of job satisfaction among nurses were examined.

\section{Significance}

Job satisfaction is a complex phenomena recently acknowledged by the multiple variables. It has a negative relationship with intension to leave the job in severe cases. The main objective of any health outfit is to give quality care. To meet such goals the institution should strive to enhance quality and sustain it through having a dedicated and conscientious staff (Verplanken 2004).

However quality of care is still low and many factors contribute to it especially by job dissatisfaction.

Understanding about job satisfaction of nurses and influencing factors will help set up and develop appropriate strategies and programs not only leading to better job satisfaction of nursing work force but also increase their productivity efficiency and the quality of care which will improve patient satisfaction (Saifuddin 2008).

\section{Research objective}

To determine job satisfaction among nurses in Federal Medical Centre (FMC), Umuahia. 


\section{Specific objectives}

1. To measure job satisfaction among nurses in FMC

2. To describe the socio-demographic factors of nurses in FMC

3. To identify the relationship between the demographic factors and nurses job satisfaction.

\section{Research question}

1. What is the level of satisfaction among the nurses in FMC

2. What are the determinant factors for job satisfaction among nurses in FMC

\section{Limitation}

The researcher used only a randomly selected sample of the nurses' population in FMC. Socio-demographic data were not correlated with the variables. This is because of the time frame of the study.

\section{Assumption}

It is assumed that the study will reveal a low level of job satisfaction among nurses. But this may not be outright, bearing in mind the new intervention of the organizational board that are bent on improving the well being of the nurses by promotion and other incentives.

\section{Scope of Study}

The study is on nurses working in FMC Umuahia. Some variables used are only 6 variables to measure job satisfaction.

\section{Operational definition}

1. Job satisfaction is a degree to which nurses individually feel positive or negative about his/her job responsibilities, task requirement, relationship with others, working atmosphere, reward, punishment, facilities, welfare and promotion at work. It is an emotional response to their task or their responsibilities.

2. Nurses refer to the health practitioners in FMC with academic certificate or degree of proficiency in nursing.

3. Supervision is a style to oversee workers, give suggestion, provide justification, accept opinion and solve problems by using technical skills and feedback mechanism.

4. Policy and Administration, means the managing and administrating the organization, empowerment, inter-personal communication with clear direction to authorize power to operate the task until it is done.

\section{Literature review}

This will be discussed in three parts,

- Concept of job satisfaction.

- Theoretical Framework

- Factors determining job satisfaction

Job satisfaction according to Demur (2002) and Murrel (2008), is either contentment or discontentment that employee feel for a job and a concept that has an important impact on organization. Al-Hussan(2008 and Bhuian (2002), opined that it is an attitude that individuals have about their jobs. They pointed out that it is an extent to which one feels positively or negatively about the intrinsic and or extrinsic aspect of one's job. The definition by Vroom 1994 is the result that the person has in participating in the job that they are doing; positive attitude will show the satisfaction of the condition of the job. This negative and positive attitude to work was equivalent to job satisfaction. On the other hand, Iskandor (2001) identified job satisfaction as critical factors in an organizational behavior. There is a great need to monitor this closely to avoid the untoward event emanating from it like decreased morale, lack of motivation. 
South American Journal of Management

Special Edition 2016

\section{Theoretical framework}

Theoretical models of jobs satisfaction include, Affect Theory developed by Edwin. The main premise of this theory is that satisfaction is determined by a discrepancy between what one wants in a job and what one has in a job, it states that what one values in a job depends on what motives his/her satisfaction.

Another important theory is the dispositional theory which suggests that people have innate disposition that came them to have tendencies towards a certain level of satisfaction regardless of pones job.

Tow factor theory by Fredrick Herzbegs attempts to explain satisfaction and motivation in the workplace. This theory states that satisfaction and dissatisfaction are driven by different factors-motivation and hygienic factor. Motivational factors are those things that drive individuals to perform e.g. Promotion opportunities, recognition achievement in work and they are considered intrinsic in origin hygienic features include the aspect of the working environment such as pay company/organizational policies supervising practices and other working conditions.

\section{Factors affection job satisfaction}

Citing Saifuddin (2008), working condition has to be consistently positively correlated with job satisfaction. Factors that affect job satisfaction include socio-demographic factors, educational level, years of working experience and marital status. The higher the nurse is educated the more skilled and high performance challenge and creative he is. Murrel et al( 2008), Demur(2002), opined that the factors that generally influenced job satisfaction is made up of management stress and policies , communication, participation in decision making, management feedback and appraisal, advancement, wages and compensation at work, promotion and displacement. When these conditions are positive, there is the possibility of increasing the satisfaction of work for nurses.

Furthermore, Noordin (2009) explained that the main determinant factors of job satisfaction range from socio-demographic factors as age, marital status and educational level and years of experience. It is assumed that job satisfaction is increased with age whereas; lowest satisfaction was reported by youngest workers. Marital status has a role to play as it is believed that married nurses do receive emotional and mental support from their spouse. Saifiddin (2009) concurred by saying that job satisfaction tend to increase with the level of education. This is more imperative with acquiring a specialty skill. Professional training is aimed at consolidating and building up skills and knowledge. This is gained through provision of continuing professional academic training.

Noordin 2009, also reiterated that attitude are affected in part by work place conditions such as a positive and safe work environment, supportive administration, career progression, salary, work teams, peers and the job itself. Other factors included by Demur (2002), Muhammed and Jamila (2008),Purani and Sahadir (2007) are motivation and hygienic factors that include salary, promotion, feedback by supervisor, co-worker and management style.

Purani etal 2007 says that job satisfaction is characterized as a multidimensional with six facet of job satisfaction whose content includes satisfaction with variety of job, supervisor, closure, compensation, co-worker and human resources/management (HR/MGM) policies.

Human interaction at work is opportunity and requirement presented for both formal and informal social content during working hours. This interaction involves reciprocity expectation. As a result there is a stable or continuing relationship developing between co-workers. The strongest support an employer may get is from co-worker, though a supervisor traditionally is responsible for supporting the employee. Helping individuals believe that the work they are doing is important and that their task are meaningful is a most important employee mobilization. Quiang (2005).

As posited by mohammed etal 2009 , most comprehensive and widely used measure for job satisfaction is presented by purani etal 2007 , this is adopted in this study.

Job satisfaction is an important work-related attitude in occupational research (boles 2003). 
It is directly related to organizational commitment and / or indirectly related to turnover. More importantly, job satisfaction can influence a variety of important attitude, intensions, and behaviors. A number of characteristics of job must be evaluated to measure job satisfaction. The characteristics may not mean same to the nurses in general. The reason being that a nurse may indicate satisfaction with supervisor but ranks low with HR/MGM policies (Muhammed etal 2008 and Murrel 2008).

\section{Summary}

The literature has successfully looked into the aspect of the subject matter and has tried to give a clear idea of what is all about. The theoretical background was based on Affect theory, Herzbeg's $t$ two factors, and dispositional theory. The general concept and the factors that are predictors of job satisfaction were highlighted.

\section{Methodology}

\section{Research design}

This is a cross-sectional study that was designed to assess the level off job satisfaction among Nurses.

\section{Study setting}

This study was conducted at the Federal Medical Centre (FMC) Umuahia Abia State.

\section{Target population}

This is made up of 301 registered Nurses working in FMC Umuahia

\section{Sample and sampling technique}

The potential number of Nurses participating in this study was 200. Power and precision was used in selecting the sample size. With sample size of 200 the standard deviation was 1.4, missing $\% 2$, margin of error; 0.10 , precision of 0.19 with the power of $99.9 \%$ to get a statistical significant result at $95 \%$ confidence interval of 33.11 to 33.4 .

\section{Instrumentation}

Data were collected in conjunction with research project on job satisfaction among nurses. The potential number of nurse participating in the study was 200 of 200 questionnaire sent out 197(98.5\%) were returned. However only 193 were found completed and were considered for data analysis giving a response rate of $96.5 \%$.

The method of data collection was a self-administered questionnaire. This contained various socio-demography data, factors determining job satisfaction as main variable and subcategories of each main variable. The measures of the variables were subjective: there is a strong case for arguing that the perceptions of the subject are important as job satisfaction may be largely an individual subjective reaction to his/her job environment. This is because a nurse may indicate high satisfaction with supervisor, but "rank" low with management policies. (Muhammed et al 2008).

Attitude developed by an employee may be associated to work, general work content and organizational serpents. (Johnson 2002).

Self-reported job satisfaction level was measured by the question. Are you satisfaction with your job variety, supervisor closure compensation, co-workers and Human Resource/Management Polices?

The response was from lowest (1) to highest (5). Based on the responses the participants were categorized into one of the three following groups; 2.5 low satisfactions, 3.5 moderate and 4 high satisfactions.

The questionnaire response were categorized into strongly disagree (1), disagree (2) indicated (3) agree (4) and strongly agree (5). 
South American Journal of Management

Special Edition 2016

\section{Method of data analysis}

Descriptive statistical technique was used to analyze the data. Data were presented in percentages, frequencies and mean figures.

The SPSS for MS window release 16.0 programme was used in the calculations and the minimum significance level set to $5 \%$. Significance difference was determined by spearmen, chi square and pearson's correlation test. The analysis of reliability of the item was based on cronbach's alpha. According to Bruin (2006) if the cronbach's alpha is less than 0.6 it means that the instrument used has a low reliability. If alpha value is within 0.7 the instrument shows satisfactory internal validity and acceptable. The cronbach's alpha for the scale of instrument of the study is 0.706 which gives it a high level of reliability.

\section{Ethical considerations}

The respondents were made to understand that the aim and objective of the project and that they will not be held responsible or liable for any information given. Collected information will be treated with utmost confidence and will be used for academic purpose.

Research result and findings.

\section{Result and analysis}

Table 1. Descriptive result of the socio- demographic data $n=193$

\begin{tabular}{|l|l|l|}
\hline & Frequently & Percentage \\
\hline Female & 189 & $97.9 \%$ \\
\hline Male & 4 & $2.01 \%$ \\
\hline Age & & \\
\hline $20-30$ yrs & 41 & $21.24 \%$ \\
\hline $31-40$ yrs & 72 & $37.3 \%$ \\
\hline 41 yrs and above & 80 & $41.45 \%$ \\
\hline Age mean 64.3 & 50 & 2.5 \\
\hline Marital Status & & \\
\hline Married & 92 & $47.7 \%$ \\
\hline Single & 101 & $52.3 \%$ \\
\hline Highest Qualification & & \\
\hline RN/RM & 91 & $47.15 \%$ \\
\hline Diploma in any specialty & 57 & $29.5 \%$ \\
\hline Degree and above & 45 & 23.3 \\
\hline Working experience in years & & \\
\hline $0-4$ years & 40 & $20.73 \%$ \\
\hline $5-10$ years & 68 & $35.23 \%$ \\
\hline $11-19$ yrs & 45 & $23.32 \%$ \\
\hline 20 and above & 40 & 20.73 \\
\hline
\end{tabular}

Among the respondents $97.9 \%$ were female while $2.01 \%$ were males. This,finding indicates that the workforce is predominantly female. Age distribution range from $20-4$ years $21.24 \%$ of the nurse were age $20-30$ years. $37.31 \%$ were aged $31-40$ years and $41.45 \%$ were aged 41 years and above. Among the respondents, $47.15 \%$ had been educated up to registered Nurse/Midwife. $29.3 \%$ had Diploma in a specialty area in nursing while $23.3 \%$ had trained to degree level. Majority $52.3 \%$ are singe while $47 \%$ are married. $20.73 \%$ have been working for $1-4$ years, $35.23 \%$ for $5-10$ years $23.32 \%$ for $11-19$ yrs and $20.73 \%$ for 20 years and above. This shows the profits of the respondents who formed as the general populations of nurses in FMC. The finding can be generalized. 
Table 2. Is the descriptive analysis of the main variables and its subcategories of the study.

\begin{tabular}{|l|l|l|}
\hline & Mean & SD \\
\hline Satisfaction with job & 4.2 & 1.73 \\
\hline Satisfaction with supervisor & 3.5 & 2.17 \\
\hline Satisfaction with closure & 3.9 & 1.05 \\
\hline Satisfaction with compensation & 2.56 & 0.88 \\
\hline Satisfaction with co- worker & 3.99 & 1.44 \\
\hline Satisfaction with HR/MGM policies & 3 & 1.66 \\
\hline
\end{tabular}

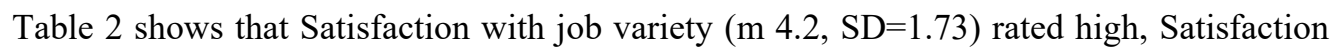
with supervisor $(m=3.5 \mathrm{SD}=2.17)$ with moderate satisfaction. Satisfaction with closure $(\mathrm{M}+3.9$ $\mathrm{SD}=1.05)$ moderate. Satisfaction with compensation $(\mathrm{M}=2.56 \mathrm{SD}=0.88)$ rated low satisfaction. Satisfaction with co-workers $(\mathrm{m}=3.99 . \mathrm{SD}=1.44)$, moderate. Satisfaction with human resource/management polices $(\mathrm{m}=3 \mathrm{SD}=1.66)$ shows low satisfaction.

Table 3. Description result of the subcategories of the main variable $(n=193)$.

\begin{tabular}{|l|l|l|}
\hline Items & Mean & SD \\
\hline Descriptive Result of Satisfaction with job variety. & & \\
\hline i. My job has enough opportunity for Independent thought and action. & 3.9 & 2.01 \\
\hline ii. There is enough variety in my job. & 4 & 1.2 \\
\hline iii. I have enough freedom to do what I want to do in my job. & 4 & 2.5 \\
\hline iv. I am satisfied with the opportunity my job provides me to interact with others. & 4 & 2.03 \\
\hline Total mean & 3.98 & \\
\hline Descriptive Result of Satisfaction with supervisor. (n=193) & & \\
\hline i. I am satisfied with the information from my supervisor about my job. & 3.99 & 2 \\
\hline ii. There is enough opportunity to interact with my boss. & 4 & 3 \\
\hline iii. I receive enough feedback from my supervisor. & 3.14 & 3 \\
\hline iv. I receive enough information about my performance. & 3.9 & 2.4 \\
\hline Total & 3.6 & \\
\hline Descriptive Result of Satisfaction with closure. (n=193) & & \\
\hline i. My job has enough opportunity to complete the work started. & 4 & 1.4 \\
\hline $\begin{array}{l}\text { ii. I am satisfied with the opportunity my job gives to complete the task from start } \\
\text { to finish. }\end{array}$ & 4 & 3.15 \\
\hline Average mean & & \\
\hline Descriptive Result of Satisfaction with compensation.(n=193) & 4 & \\
\hline i. I am satisfied with the organization compensation package. & & \\
\hline ii. I am satisfied with the medical benefits. & 3.7 & 1.8 \\
\hline iii. I am satisfied with the holiday eligibility. & 4.4 & 1.7 \\
\hline iv. I am satisfied with the security my job provides me. & 4 & 1.07 \\
\hline Total mean & 4 & 1.4 \\
\hline Descriptive Results of Satisfaction with co-workers. (n=193) & 4.02 & \\
\hline i. My fellow workers are pleasant. & & \\
\hline ii. My fellow workers are not selfish. & 3.9 & 3.9 \\
\hline $\begin{array}{l}\text { iii. The people I work with help each other out when someone falls behind or gets } \\
\text { in tight sport. }\end{array}$ & 3.9 & 4.16 \\
\hline iv. The people I work with are very friendly. & 3.7 \\
\hline Total & 4.02 & 2.6 \\
\hline Descriptive Results of Satisfaction with HR/MGM Polices. (n=193) & 3.9 & \\
\hline i. Hospital management has a clear path of nurse advancement. & & \\
\hline ii. Physical working conditions are supportive in attaining quality care. & 3.9 & 2.0 \\
\hline & 3.96 & 1.5 \\
\hline
\end{tabular}


South American Journal of Management

Special Edition 2016

\begin{tabular}{|l|l|l|}
\hline iii. Management is extremely fair in personnel policies. & 3.3 & 2.3 \\
\hline iv. Decisions are made keeping in mind the good of the nurses. & 4 & 2.1 \\
\hline Total mean & 3.79 & \\
\hline
\end{tabular}

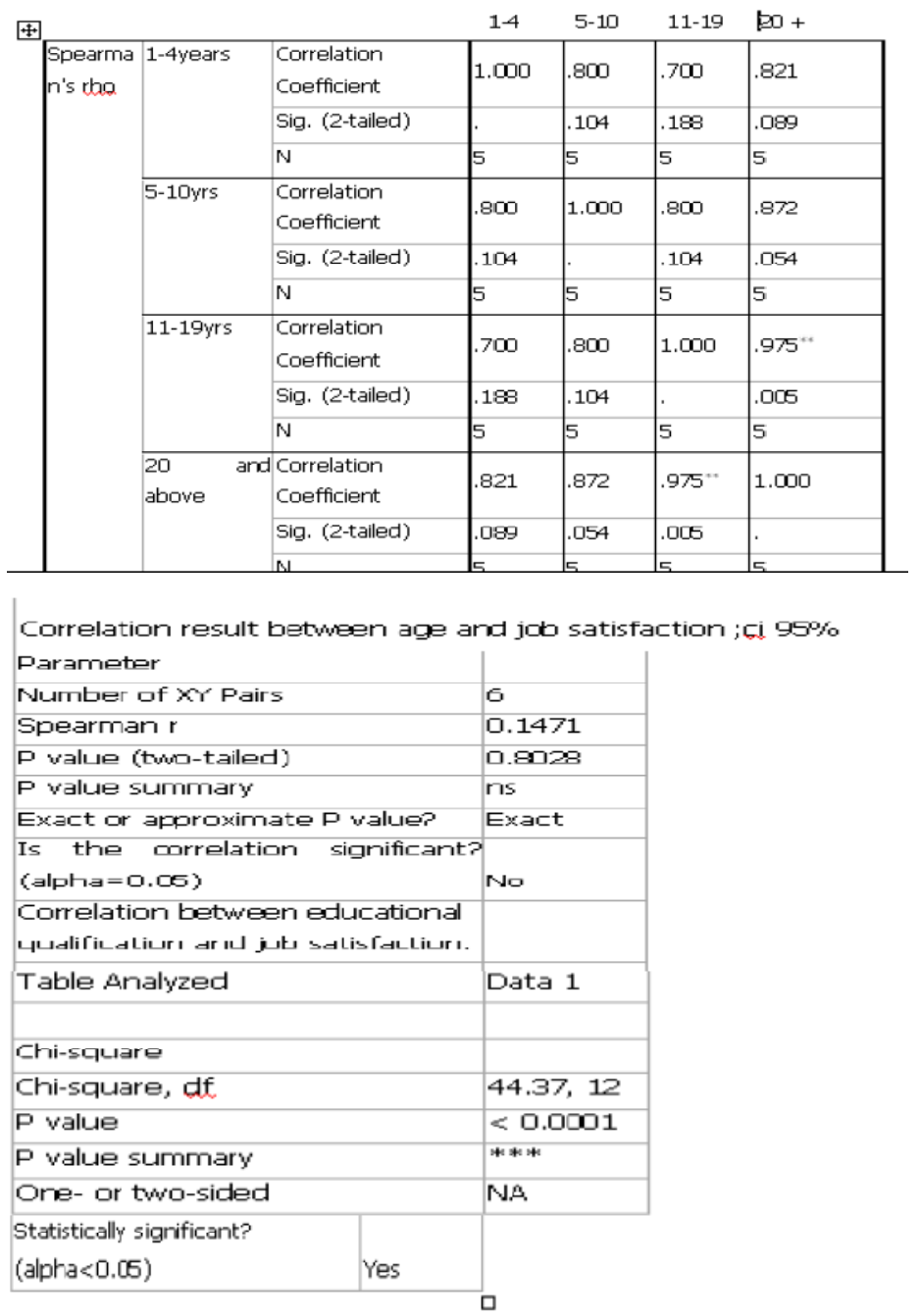

Correlation between marital status and job satisfaction.

Pearson's $\mathrm{r}-0.7491$

Confidence interval at $95 \%-0.3930$

P-value -0.1451; alpha -0.05

Correlation significance -no

\section{Discussion, summary and recommendation}

\section{Discussion}

Referring to table III for details of level of each variable of job satisfaction four items were used for each of the major variables to determine how nurses perceive satisfaction at work.

Table IIIa is a highlight of descriptive statistics of job variety. Four items were used to measure nurses' perceived satisfaction. Three of the items, variety in my job, freedom to do what I want and satisfaction with the opportunity my job provides me to interact with others has Mean 4 each, SD of 1.2, 2.5 and 2.03.my job has enough opportunity for independent though and action, $(\mathrm{m}=3.9, \mathrm{SD}=2.01)$. Average mean $=3.98$ which reveals a high level of satisfaction with job variety.

Table III $b$ highlights descriptive statistic of satisfaction with supervisor. There is enough 
opportunity to interact with my boss shows highest mean $(\mathrm{m}=4 . \mathrm{SD}=)$, followed by $\mathrm{I}$ am satisfied with the information from my supervisor about my job $(\mathrm{m}=3.99, \mathrm{SD}=)$, I receive enough information about my performance $(\mathrm{m}=3.9, \mathrm{SD}=)$. While I receive enough feedback from my supervisor has the lowest mean $(\mathrm{m}=3.14, \mathrm{SD}=)$ ) The average mean is 3.6 which reveals that the nurses' perceive level of satisfaction with supervisor is just at moderate level.

Table III c highlights the descriptive statistic of closure. Two items were used to measure level of satisfaction. The nurse's perceived level of satisfaction is high with opportunity to complete started task $(\mathrm{m}=4, \mathrm{SD}=1.4)$, opportunity to complete job from start to finish $(\mathrm{m}=4$, $\mathrm{SD}=3.1)$.In general the average mean reveals a high satisfaction level $(\mathrm{m}=4)$ It indicates that the hospital provided enough opportunities in the support of the nursing staff to be able to complete given tasks.

Table III $d$ is the descriptive statistic of satisfaction with compensation. Four items were used to measure the satisfaction level on compensation. Nurses felt relatively higher level of satisfaction with medical benefit $(m=4.4 \mathrm{SD} 1.7)$, followed by holiday eligibility $(m=4 \mathrm{SD}$ 1.07), and job security ( $m=4$ SD 1.4). The satisfaction level perceived with compensation package is moderate $(m=3.7 \mathrm{SD} 1.8)$. Generally the result showed that the nurses have highest mean value of 4.02. The indication is that the management had put everything in place as an inducement to motivate the nurses at workplace to achieve organizational goal.

Table III e is the descriptive statistic of satisfaction with co-worker. The four items reveals the respondents perceived level of satisfaction. The people I work with are very friendly $(m=4.02$ SD 2.6) has the highest mean, followed by "the people I work with help each other $(m=3.96$ SD 3.7). My fellow workers are pleasant $(m=3.9$ SD-3.9).However, helping co-workers has a very low level of satisfaction. The average mean for co-workers is 3.9. this shows that the perceived level of satisfaction with co-workers is moderate -high. It is assumed that the nurses are supportive to their fellow nurse providing a healthy and collaborative effort.

Human resource /Management policies is statistically described in Table III f. Highest level of satisfaction is shown with decision in keeping with the nurses in mind. ( $m=4$ SD 2.1) followed by physical working condition are supportive ( $m=3.96 \mathrm{SD} 1.5)$, and hospital management has clear path of nurses advancement $(\mathrm{m}=3.9 \mathrm{SD}=2)$. Fair personal policies by the management revealed a very low level of satisfaction $(\mathrm{m}=3.3, \mathrm{SD}=2.3)$.

Generally, the result of the study showed a moderate to high level of satisfaction among the nurses which gives a picture of the nurses coping with almost all the environmental factors of workplace. This is in line with literature as posited by Muhammed (2008), saifiddin (2009), Johnson et al (2000). The literature suggests that satisfaction improves with increase in years of experience Demur (2008). This may be because they are now more familiar with the job and their situation that they are not worried about it anymore. The next to consider is educational qualification. It is assumed that those with higher qualification have more skill and more confident in their job than the others. The later may face more humiliating working condition as those who can only do ordinary general duties. Surprisingly the result about age and marital status refuted the suggestion in the literature that married nurses may be more satisfied because of moral and emotional support given to them by their spouses.

\section{Summary and conclusion}

Overall, the finding of the research study has provided answers to the research questions. The findings suggest that the nurses, have mostly moderate than high level of satisfaction. Socio-demographic data have some antecedent conditions to statistic. The management can identify the factors that cause low satisfaction by using organizational climate survey.

\section{Recommendation}

Human resource policies must be improved in fairness to advancement through promotion, inducement, training and development. Integration and conducive working environment should be provided.

Hospital leadership and supervisors role should be improved and sustained. Job 
South American Journal of Management

Special Edition 2016

management, specialization, specification and enrichment are encouraged.

More time should be made available to make an in-depth correlation study about job satisfaction.

\section{References}

[1.] Adams A, Bonds (2002) Hospital nurses job satisfaction, individual and Organizational Characteristics. Journal of Advanced Nursing 2002,32(3):536543./Pub Med Abstract.

[2.] Bhuian, S.N and Menque, B (2002). Evaluation of job characteristics, organizational Commitment and Job Satisfaction in an Expatriate Guest Worker. Journal of Personal Sellind and Sales Management. $22,1-12$

[3.] Bruin J (2006). New test: Command to computer new test UCLA: Academic technology Services and Statistical Consultancy Group.

[4.] Demur C (2002). Determining the level of job satisfaction of nurses working at Turkish Military Forces Hospital. Military Medicine 2002.

[5.] Iskandor, T. A (2001). Job sites of Nurses at Health Centre in Indonesia. MPH Thesis In Public Health.

[6.] Johnson, A .J and Johnson, W .R (2000). Perceived over qualification, positive and Negative affectivity and Job Satisfaction. 15(2),167-185

[7.] Mahmoud AL-hussani 2008. A study of nurse's job satisfaction. European journal of Scientific Research vol 22 no 2 pgs 286-95..

[8.] Muhammed, A, \& Jmilha, F. M (2008.) Business intelligence journal 2010 vol. 3 no 1

[9.] Murrels, T, Robinson, S, \& Maben, J (2008). Improving job satisfaction for newly Qualified Nurses .Employment Nurses and Midwives 2008,177:2-3.

[10.] Noordin, F () 2009. Level of job satisfaction among Malaysia academic staff. Asian Social Science vol 5 no 5.

[11.] Qiang H 2005. Job satisfaction among medical staff in Weifeng Hospital in China. MPH Thesis in Primary Healthcare Management, Nakhon Pathon 2005

[12.] Saifuddin. (2008).Job Satisfaction among nurses in ACEH Timor Indonesia. Thesis Mahidol University, 2008.

[13.] Verplanken B (2004)Value Congriuence and Job Satisfaction among nurses: a human Relation perspective. International Journal of Nursing Studies. 41(2004) 599-605 